\title{
Open Access Scholarly Publications as OER
}

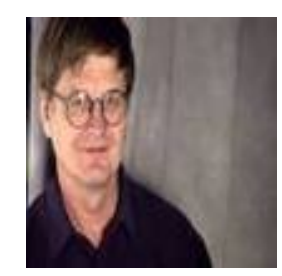

Terry Anderson

Athabasca University, Canada

\section{Abstract}

This paper presents the rationale, common practices, challenges, and some personal anecdotes from a journal editor on the production, use, and re-use of peer-reviewed scholarly articles as open educational resources (OER). The scholarly and professional discourse related to open educational resources has largely focused on open learning objects, courseware, and textbooks. However, especially in graduate education, articles published in scholarly journals are often a major component of the course content in formal education. In addition, open access journal articles are critical to expanding access to knowledge by scholars in the developing world and in fostering citizen science, by which everyone has access to the latest academic information and research results. In this article, I highlight some of the challenges, economic models, and evidence for quality of open access journal content and look at new affordances provided by the Net for enhanced functionality, access, and distribution.

In the 17 years since I graduated with a doctorate degree, the climate and acceptance of open access publishing has almost reversed itself. I recall a conversation with my $\mathrm{PhD}$ supervisor in which he argued that publishing online was not a viable option as the product would not have permanency, scholarly recognition, or the prestige of a paper publication. His comments reflect the confusion between online resources and those described as open access, but as well illustrate the change in academic acceptance and use of open access products during the past decade. The evolution from paper to online production and consumption is a disruptive technology in which much lower cost and increased accessibility of online work opens the product to a completely new group of potential users. In the case of OER these consumers are primarily students, but certainly access to scholars from all parts of the globe and the availability to support citizen science (Silvertown, 2009) should not be underestimated.

Keywords: Open education resources; scholary publications; open access 


\section{What is Open Access Scholarly Publication?}

Open access (OA) scholarly works usually assume the same formal definitions as other open access works. The most common definition is that agreed to in 2001 and referred to as the Budapest Open Access Initiative. This agreement defines open access as

free availability on the public Internet, permitting any users to read, download, copy, distribute, print, search, or link to the full texts of these articles, crawl them for indexing, pass them as data to software, or use them for any other lawful purpose, without financial, legal, or technical barriers other than those inseparable from gaining access to the Internet itself. (http:/ / www.earlham.edu/ peters/ fos/ boaifaq.htm\#ope naccess)

The focus of this definition on access and redistribution rights has tended to conflate OA resources and thus limited OA to materials available only on the Web. Although the vast majority of open access scholarly works are published on the Web, scholarly works can be published and distributed in any medium. For example, the millions of texts whose copyright has expired can be, and many are, published in print, online text, and audio formats. However, it is certainly not true that all scholarly content distributed on the Web is open access. This becomes obvious when a reader is presented with a subscription login or an invitation to add the article to the "shopping cart". To add confusion, some scholarly content is distributed with no barriers on the open Net, even though all copyrights are retained by the publisher.

This confusion between ready access and legal use results in a serious challenge to educational and research efficacy. This is underlined in a 2008 study of American K12 teachers that concluded

The major finding of the study was that the key goals of teaching media literacy were "comprised by unnecessary copyright restrictions and lack of understanding about copyright law" (p. 1). Because of participants' lack of knowledge and understanding about the law's protections, their ability to share, teach, and have students produce media-rich texts was severely circumscribed. Not only that, but the researchers found that teachers' lack of knowledge was passed on to students as well as colleagues, perpetuating "copyright folklore" that often characterized the law as much more restrictive than it is. (Rife, 2008) 
Thus, it is apparent that the educational community needs both a better understanding of copyright and adoption of practices that harness these resources for maximum education and scholarly benefit. A first step is to understand the licensing that must accompany open access publications.

\section{Licensing Open Access Scholarly Work - Creative Commons Licenses}

Unlike open source software, scholars generally have more concerns about allowing their work to be modified. The licensing model most often used was created by Creative Commons and retains copyright by the author or, if copyright has been surrendered, by the publisher. However there are a number of additional rights that are detailed in the particular license attached to the work.

CC BY: The most permissive, and thus open license, restricts rights to copy and share and only requires attribution to the copyright owner - owned BY. The CC BY license allows for reuse of the content including modifying, adding, or deleting portions and redistributing in any format. Content licensed with only the Creative Commons attribution restriction, the CC BY license, is sometimes referred to as open content.

CC ND : Some authors and publishers use an additional restriction that stipulates no derivatives such as edits and additions.

CC NC : The copyright owner can also include a noncommercial restriction that prohibits others from selling or bartering the copyright product.

CC SA : This share alike restriction allows the user to share the copyright material, if it is relicensed under the same licensing agreement adopted by the copyright owner.

All of these rights retained can be added together to create a legal license (linked to at http:// creativecommons.org/) that has many combinations, for example CC BY-ND-NC.

In my work as editor of The International Review of Research in Open and Distance Learning (http:// www.irrodl.org), we initially adopted a CC BY-ND license as we felt that the tradition associated with scholarly publication was to quote sections (with attribution) rather than add to or make derivative products. However, the widely respected Scholarly Publishing and Academic Resources Coalition (SPARC) required use of the CC BY to win its "OA gold seal". Upon reflection we considered that removing restrictions likely was in the interests of both our readers and our authors and thus changed our licensing requirements to attain the gold OA seal. 


\section{Gold and Green Standards of Open Access}

A long time open access evangelist, Stephen Harnad, argues that there are two roads to OA: the "golden" road or standard (publish an article in an OA journal) and the "green" road (publish your article in a non-OA journal but also self-archive it for access by all in an OA or institutional archive, such as those listed at http:// www.opendoar.org//). He contends that $90 \%$ of journals allow self-archiving and thus are in effect "open access" however data from the more definitive RoMEO database from the University of Nottingham refutes that claim (Figure 1) and shows that in May 2013, of 1,245 publishers publishing over 18,000 journals, only $69 \%$ allow some form of self-archiving.

\section{SHERPA/RoMEO Colours, excluding provisional policies}

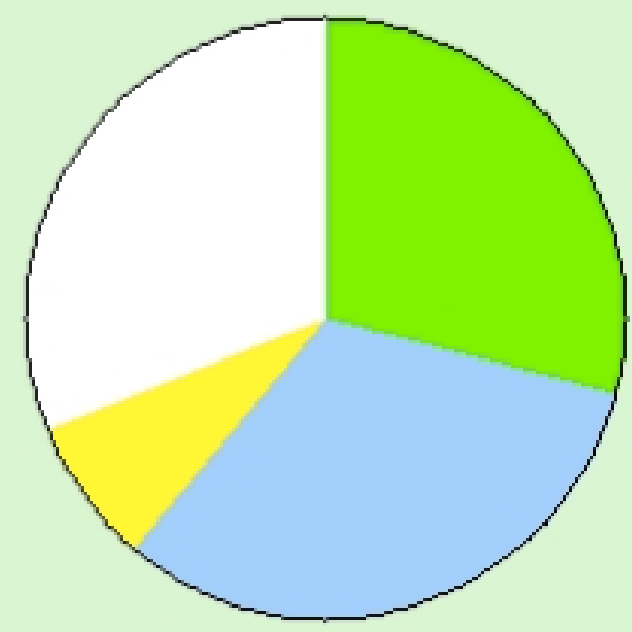

$\square$ Green $(366=29 \%)$

$\square$ Blue $(396=32 \%)$

$\square$ Yellow $(97=8 \%)$

$\square$ Hhite $(386=31 \%)$

ROMEO colour

green

blue

yellow

white
Archiving policy

Can archive pre-print and post-print

Can archive post-print (ie final draft post-refereeing)

Can archive pre-print (ie pre-refereeing)

Archiving not formally supported
Publishers \%

366

396

97

386

\section{9}

32

8

31

Figure 1. RoMEO Database summary figures of journal publisher self-archiving policy (from http:// www.sherpa.ac.uk/romeo/statistics.php CC-BY-NC-SA).

The RoMEO Project with a mandate to help create an "environment in which Open Access will become the norm for distributing research" proposes and endorses an 
"Immediate Deposit, Open Access policy" by which institutes that employ scholars require an archive copy of any publication be stored in a content repository, immediately upon publisher acceptance. They argue that "This IDOA policy is greatly preferable to, and far more effective than a policy that allows delayed deposit (embargo) or opt-out as determined by publisher policy or copyright restrictions" (http://www.eprints.org/).

To enable champions of OA to review OA policies from other institutions, the Eprint project sponsored by the University of Southampton hosts a repository of institutional access policies (http://roarmap.eprints.org/). Thus we see a growing institutional acceptance and a variety of tools to manage open access distribution, even for scholarly works published in proprietary and closed publications. However archiving policies, such as the IDOA policy, allow for academic access, but preclude re-publication in course guides or other forms of educational content.

\section{Rationale for $\mathrm{OA}$}

The growing interest by scholars, librarians, funders, and foundations in OA is motivated by a variety of sometimes divergent interests. I briefly overview these motivations in the following section.

\section{Citizen science.}

Citizen science is perhaps as old as human knowledge itself and consists of ordinary people working alone or together to resolve problems using basic or increasingly sophisticated tools and techniques of science. Silvertown (2009) lists three reasons for the explosion of citizen science in the last decade. The first is the availability of powerful new tools allowing everyone to participate and contribute to "real science" projects. The second is the growing awareness of the value in work produced by distributed volunteer labor pools and the associated ingenuity of these diverse networks. The third is a growing government and sponsor interest in disseminating or translating science and its results to the citizenry. Open journals facilitate and support citizen science in all three areas listed by Silvertown. The free distribution of results in open access scholarly publication allows citizens to become informed, educated, motivated, and in other ways engaged in cutting edge scientific research. Second, open access provides a tool for recruitment and training of potential citizen scientists and, finally, funders are realizing and in some cases requiring that grant funded science be returned and repaid to the taxpayers partially through open distribution of results.

\section{Open science.}

The vision of open science "is to make clear accounts of the methodology, along with data and results freely available via the Internet" (Wikipedia, Oct. 2011). Too often data sets, detailed descriptions of both successful and failed projects and the results of scientific work, are never made public, resulting in much waste and unnecessary duplication of scientific effort. Thus, there is growing support for a variety of open data 
projects (see for example the Open Science project, www.openscience.org, and the Open Students network, http:// www.openstudents.org//). There is also increasing evidence of the value of students participating in, instead of watching and summarizing, the work of others (Pascarella \& Terenzini, 2005). Open science projects aim to make this process easier and more accessible by not only disseminating the results of student work, but also by making the process by which science is conducted more visible to learners.

\section{Expanding access.}

Many academics receive all or the vast majority of their personal income from the educational institution that employs them or from a related research grant. Unlike commercial authors, these creators are not primarily motivated by the prospect of financial return, partially because they benefit from a substantial institutional economic security blanket. For most academics publishing is motivated by peer recognition that is translated into institutional raises and promotions, opportunities for travel, and occasionally small fee for service contracts. Thus, the prospect of tens or hundreds of thousands of online readers is more attractive than tens or hundreds of readers of printbased journal products.

\section{Special needs of developing countries.}

The case for extending access to academics in developing countries and to those amateurs and professionals throughout the world who are not associated with a university or government research library is both compelling and obvious. Even a small university such as my own (Athabasca University), with fewer than 150 full time academics, spends over $\$ 350,000$ annually on subscriptions to commercial journal data bases. The more widely knowledge is circulated, the more likely it will be applied to solve problems and enhance quality of life on this planet. The gap between demand for higher education opportunity and provision by the public education systems or at affordable rates from the private sector is large and growing (Altbach, Reisber, \& Rumbley, 2009).

Other articles in this special issue overview the opportunity and remaining challenges of both improving quality and decreasing costs through the use of open educational resources for teaching and learning. But there is an equally compelling need for publication opportunities for scholars in the developing world. Unless these countries are actively producing as well as consuming knowledge, they will be relegated to new forms of colonial dependency. Open access solutions that require large author fees for publication will also act as a disincentive for scholars from developing countries.

None of the rationales above fuel the profits that publishers have enjoyed from proprietary models of academic publishing, thus I turn next to a more detailed look at the business case of open access scholarly publication. 


\section{Business Case}

Many years ago Karl Marx argued that those who produce the goods should benefit the most from their production. Obviously in the neo-capitalist world in which we live there are many exceptions to this principle. However, the case of academic publishing is especially egregious.

The normal academic publishing model for scholarly work sees the academic submitting his work to a publisher (at no charge to the publisher), the article being reviewed by a team of volunteer editors and reviewers (again, at no charge to the publisher), and then the author (or his or her educational institution) having to pay large fees to access the published work. In the UK the cost of these journal subscriptions now represents $65 \%$ of the total library budget ("Academic publishing: Of goats and headaches," 2011). Given the real work of copyediting and electronic distribution, a case can be made for a fair return on investment and profit for scholarly publishers. However, the journal publishing sectors of the major publishers are their most profitable divisions. For example, the world's largest publisher Elsevier made “ $€ 724 \mathrm{~m}$ ( $\$ 1.1$ billion) on revenues of $£ 2$ billion - an operating-profit margin of 36\%” (see http:// www.economist.com/node/ 18744177).

It seems obvious that reform within this industry is long overdue and that excessive profit-taking on the part of the commercial publishers in this sector must be challenged and eliminated.

\section{Who Pays for Open Access}

OA publication is nearly always done electronically and thus is usually cheaper to produce than print production; however, it is not cost free. The Budapest Open Access Initiative FAQ puts it succinctly:

Free is ambiguous. We mean free for readers, not free for producers. We know that open-access literature is not free (without cost) to produce. But that does not foreclose the possibility of making it free of charge (without price) for readers and users.

There are a number of models for generating revenue to cover the cost of production including both supply side funding (payment by procures) and demand side funding that is accrued in some form through the readers' use. A detailed list of revenue models for publishers is provided by SPARC at http://www.arl.org/sparc/publisher/incomemodels/. I describe briefly the most commonly used in 2012:

- charging authors a publication fee (for example, 2011 PLOS fees range from \$1,350-\$2,900 US/article ( policy/publication-fees/); 
- sponsorship by a society, institution, government, or foundation (for example the American Educational Research Association distributes freely the full text of articles published in Educational Researcher, even though they pay Sage for publishing these articles);

- additional products or services sold, with the OA content given away as a sort of "loss leader" or as an inducement to purchase enhanced goods; in a 2010 study of open access text books published by Flat World Publishing, Hilton and Wiley (2010) report that 39\% of students purchased hard copies of assigned texts, even though electronic versions were available at no charge;

- $\quad$ advertising - by far the most significant source of funding for all services delivered at no charge on the Internet, but a model as yet not often used in conjunction with OA publishing;

- fund raising - many open source software projects raise funds through solicitations from users; Wikipedia has resisted both charging and advertising, but expends considerable efforts on fund raising.

But within the question of appropriate cost and funding lies the question of value. Are OA publications of as high a quality as those published under proprietary models?

\section{Effectiveness of Open Access Publication}

There have been a number of studies carried on over the last decade to attempt to determine if open access articles are cited more often than those distributed under closed publication models. Many of these studies have focused on a particular discipline or upon a wider aggregation of related journals (such as all physical sciences). The results of these examinations have not been consistent.

In many studies that compare the citation rates for articles published in open access versus proprietary journals, the proprietary journals are significantly older. Since publication longitivity is related to prestige and acceptance on library shelves and in publishers' databases, it is not surprising to find that closed articles will be cited more often - simply because they are assumed to be of higher worth, given the older and more prestigious publications in which they appear. Despite this bias, a study conducted by Zawacki-Richter and me in (2010) found a small, but not significant, increase in average citations per article published in open access journals. There was however a significant trend showing a growing citation advantage for OA publications in recent years.

To reduce this potential bias a number of researchers have compared articles in which the authors have purchased the freedom of their articles by paying the fee to the publisher that is often paid by the university, grant, or commercial sponsor of the research. In a study of 4,388 biology papers published between May 2004 and March 2006 in the Proceedings of the National Academy of Sciences (PNAS) Gaule and Maystre (2011) found that there was an increase in citations for open access papers (OA 
was available as an option for authors for a fee of $\$ 1,000$ US). However they argued that the reasons for this increase are not obvious. They noted that open access publication is a result of self-selection and diffusion effects - "open access is relatively more attractive to authors of high quality papers and thus open access papers tend to be of higher quality on average" - thus explaining their higher citation rates.

However Davis (2011) conducted a study of 3,245 science, medical, and social science and humanities journal articles of which 712 articles were randomly assigned to an open access treatment group. Interestingly this study compared both the downloads (in a variety of formats) and the citation rates. The results showed that

Articles placed in the open access condition $(n=712)$ received significantly more downloads and reached a broader audience within the first year, yet were cited no more frequently, nor earlier, than subscription-access control articles $(n=2533)$ within 3 years. (p. 2129)

Davis argues that the increased readership is a result of consumption from a much wider community of amateur, professional, industry, and government readers who do not have access to the funds and laboratories to conduct their own research, but are nonetheless a significant stake holder in the dissemination community. I would argue that in professional and applied communities this non researching but critical group of appliers and translators of research knowledge is in fact more important in implementing change than the elite research community who produce new knowledge and the citations that accompany its dissemination.

Davis's (2011) study alerts us to the challenges of equating impact with citations, however the issue is even more complicated when one looks at the means by which citation rates and resulting impact factors for journals are calculated. Most contentious is determining what literature to index. The most well known and prestigious citation indexer is Thompson/ Reuters World of Science (WoS). I've written earlier (Anderson \& McConkey, 2009) (note how easy it is to gain a citation - even a self-reference!) about the bias of commercial publishers against open access publishers and their reluctance to include new open access journals in their citation indexing systems. But not withstanding this bias is the challenge of finding all the relevant materials. Some publishers make this easy by indexing only publications from a subset of journals that they have determined are of high quality. This seems a sound rationale as citation in a web-based high school term paper hardly qualifies as evidence of a contribution to new knowledge production. But there are many scholarly contributions often cited as grey literature (conference proceedings, white papers, key note speeches, etc.) or that appear in monographs and textbooks - and none of these citations qualify in most of the major indexers. However Google Scholar and other automated search engines do traverse the grey literature and produce citation rates that are normally higher but arguably more accurately representative of true academic dissemination. Kousha and Thelwall (2008) argue that the wider coverage should be "considered to be an advantage 
of Google Scholar, since it could be useful for citation tracking in a wider range of open access scholarly documents and to give a broader type of citation impact." In a 2008 study Vaughan and Shaw searched a sample of 1,483 publications from the American Library and Information Academics journals and compared citation ratings among open Google searches, Google Scholar, and WoS. As expected Google Scholar had higher levels of citation and an examination of the citing articles or Web sites resulted in $92 \%$ of them being classified as "having intellectual impact" (excluding those that were advertising promotions, extracts, student papers, blogs, etc.). Interestingly, Vaughan and Shaw (2008) found an average of 3.1 citations from proprietary journal articles in WoS and only 1.0 citations/article from those published in open access journals, implying that the proprietary articles were cited more often. However, Google Scholar with its wider source of foraging of scholarly works found an average of 4.9 citations for proprietary articles compared and an average of 6.4 citations for open access journals, leading to the opposite conclusion in regard to article impact. They further found that the number of citations on the open Web (via Google search) showed even greater impact of open access publication.

As we see OA articles are distributed much more widely and have equal or better likelihood of being cited by other scholars. But are there other differences? In an interesting study Verspoor, Cohen, and Hunter (2009) compared the linguistic, grammatical, and textual characteristics of a large sample of science articles and concluded, "We did not find structural or semantic differences between the Open Access and traditional journal collections."

The data above confirms that, typical of emerging disruptive technologies (Christensen, 1997), open access journal publications have been relentlessly increasing in use and as importantly in quality as attested to by impact factors assigned to open access journals. This wider distribution and citations have many positive effects. The open access books that I have edited in the Distance Education Series for Athabasca University Press continue to generate 100's of thousands of downloads while retaining print sales that are equivalent to closed books (McGreal \& Chen, 2011). I am convinced that the increasing number of requests for visits and keynote talks that find their way to my email box is, in large degree, related to the accessibility of my openly published academic work.

\section{Beyond Open Access Publishing}

With the increasing power and sophistication of web-based tools, a number of authors and journals have attempted to further exploit the affordances of networks and the benefits of openness by expanding the review and commentary process. This expansion typically takes a variety of forms including making the names of peer reviewers public (eliminating anonymity), allowing public or community review before publication, and allowing commentary or review after publication. In his evangelical style Harnard wrote 
in 1991, "I am convinced that once scholars have tasted it" (open scholarship or skywriting as Harnard refers to it),

they will become addicted for life, as I did. And once word gets out that there are some remarkable things happening in this medium, things that cannot be duplicated by any other means, these conditions will represent for the scholarly community an "offer they cannot refuse. (p. 53)

Harnard was instrumental in the founding of Pscoloquy which incorporated open commentary, hyperlinking, and other new tools available to online journals for 12 pioneering years. Ironically Wikipedia notes in its stub article on Psychology that "Psycoloquy is currently suspended and will restart when open access prevails" (Wikipedia, Sept. 3, 2011). In the decade that Harnard and other visionaries have been waiting for open access supremacy, a number of other journals have picked up the innovators torch.

Our own attempts at allowing public, post publication commentary of articles in The International Review of Research in Open and Distance Learning (IRRODL) have largely failed. Opening the door to public commentary or review also opens access to spammers and to those with their only goal being to create a link to their own site for pecuniary interests. These challenges can be overcome, but more challenging is the simple dearth of useful comments. It seems that both readers and authors consider published articles to be finished artifacts, to be discussed (if at all) in private circles, classrooms, and as subject of later articles or reviews. There seems (at present) to be little appetite for engaged conversation using the traditional published article as a focal point. It should be noted that there are many other forums, from MOOCs to email lists, Google Circles to Linked In and Facebook, that provide potential venues for such conversations.

Nonetheless individual efforts by publishers continue and are often celebrated by early adopters. Figure 2 charts the typical two prongs (expert peers and the broader scientific community) that have input into preprint manuscripts of articles being assessed for publication using "interactive open access publishing" in the journal Atmospheric Chemistry and Physics. Although Pösch (2010) makes a strenuous case for the value of community input, he notes that only $25 \%$ of articles receive any peer review, which, though small, is (he argues) by an order of magnitude higher than commentary from post publications. 


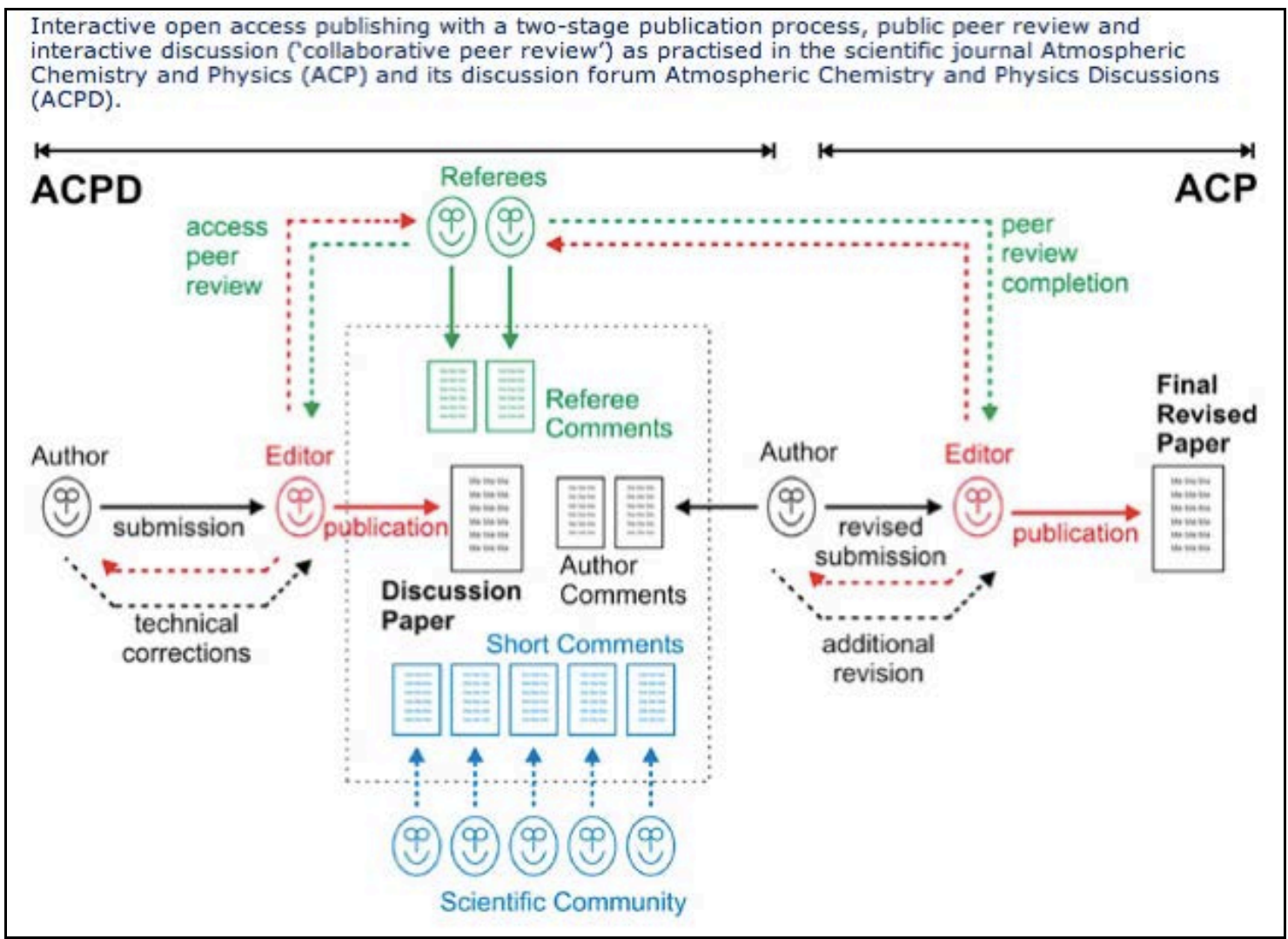

Figure 2. Model of peer and public review of scholarly articles from Pösch (2010).

Finally, there are a number of other benefits that are more associated with electronic publishing in general than strictly open access publishing. These include hyperlinks to full data sets, automatic updates to data presented in publications, and the ease of retraction or correction to published articles. For example, at IRRODL we have also been able to expand special issue collections by linking articles in the table of contents to works published later on the topic but after the special issue has " gone to press".

\section{Conclusion}

The arguments and examples detailed in this article point to the disruptive nature of OA publishing of scholarly works. Christensen (1997) described low-end disruptive technologies as ones that initially provide inferior product to that of the existing product, but at a much lower cost and much higher accessibility. The new product is typically not initially valued nor desired by established customers, but the disruptive innovation opens a door to whole new groups of consumers. Over time, the disruptive product becomes more functional and attractive until it replaces the traditional product. 
Classic examples include steamships, hydraulic elevators, desktop publishing, electronic watches and cameras, and many others.

Although academics are not known for their speed in adopting any new product, and, correspondingly, publishers are loathe to give up profitable products, we are in the midst of a rapid transition from closed to open access publishing. This disruptive transition benefits ordinary citizens and scholars in both developed and developing countries and is a major contributor to the openness and transparency associated with our networked society. 


\section{References}

Academic publishing: Of goats and headaches. (2011, May 26). Economist.

Altbach, P., Reisber, L., \& Rumbley, L. (2009). Trends in global higher education: Tracking an academic revolution. Paris: UNESCO.

Anderson, T., \& McConkey, B. (2009). Development of disruptive open access journals. The Canadian J ournal of Higher Education, 39(3), 71-87. Retrieved from http:// ojs.library.ubc.ca/index.php/ cjhe/article/ view/ 477.

Christensen, C. (1997). The innovator's dilemma - When new technologies cause great firms to fail. Cambridge: Harvard University Press.

Davis, P. M. (2011). Open access, readership, citations: A randomized controlled trial of scientific journal publishing. J ournal 2. FASEB, 29, 2029-2134. http:// doi.org/b35.

Gaule, P., \& Maystre, N. (2011). Getting cited: Does open access help? Research Policy, 40(10), 1332-1338. Retrieved from http:// www.sciencedirect.com/ science/ article/ pii/ S0048733311001065.

Harnad, S. (1991). Post-Gutenberg galaxy: The fourth revolution in the means of production of knowledge. Public-Access Computer Systems Review, 2(1), 3953. Retrieved from http:// cogprints.org/ 1580/ 1/ harnad91.postgutenberg.html.

Hilton III, J ., \& Wiley, D. (2010). A sustainable future for open textbooks? The Flat World Knowledge story. First Monday, 15(8). Retrieved from http:// firstmonday.org/ htbin/ cgiwrap/ bin/ ojs/ index.php/ fm/article/ view/ 280 $\underline{0 / 2578}$.

Kousha, K., \&Thelwall, M. (2008). Sources of Google Scholar citations outside the Science Citation Index: A comparison between four science disciplines. Scientometrics, 74(2), 273-294. http:// dx.doi.org/ 10.1007/ s11192-008-0217-x.

McGreal, R., \& Chen, N. S. (2011). AUPress: A comparison of an open access university press with traditional presses. Educational Technology \& Society, 14(3), 231239.

Pascarella, E., \& Terenzini, P. (2005). How college affects students: A third decade of research. San Francisco, CA: J ossey-Bass.

Pösch, L. (2010). Interactive open access publishing and peer review: The effectiveness and perspectives of transparency and self-regulation in scientific communication and evaluation. Liber Quarterly, 19(3/4). Retrieved from http:// www.atmospheric-chemistry-and- 
physics.net/pr_acp_poschl_liber_quarterly_2010_interactive_open_access_p ublishing.pdf.

Rife, M. (2008). The importance of understanding and utilizing fair use in educational contexts: A study on media literacy and copyright confusion. Social Science Research Network. Retrieved from http://ssrn.com/ abstract=1122624.

Silvertown, J . (2009). A new dawn for citizen science. Trends in Ecology \& Evolution (Personal edition), 24(9), 467-471. Retrieved from http://linkinghub.elsevier.com/ retrieve/ pii/S016953470900175X.

Vaughan, L., \& Shaw, D. (2008). A new look at evidence of scholarly citation in citation indexes and from web sources. Scientometrics, 74(2), 317-330. http:// dx.doi.org/ 10.1007/ s11192-008-0220-2.

Verspoor, K., Cohen, K. B., \&Hunter, L. (2009). The textual characteristics of traditional and open access scientific journals are similar. BMC Bioinformatics, 10(1), 183. Retrieved from http:// www.biomedcentral.com/1471-2105/ 10/ 183.

Zawacki-Richter, O., Anderson, T., \& Tuncay, N. (2010). The growing impact of open access distance education journals - a bibliometric analysis. J ournal of Distance Education, 24(3). Retrieved from http:// www.jofde.ca/index.php/jde/article/view/661/1170.

\section{Athabasca University $\mathbf{a}$}

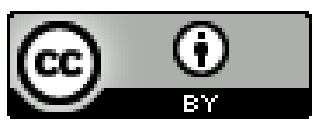

